Rama Dilip Gajulapalli, MD

Department of Hospital Medicine, Cleveland

Clinic; Clinical Assistant Professor, Cleveland

Clinic Lerner College of Medicine of Case

Western Reserve University, Cleveland, $\mathrm{OH}$
Johnny Chahine, MD

Resident Fellow, Cleveland Clinic
Florian Rader, MD

The David Geffen School of Medicine,

University of California, Los Angeles
Ashish Aneja, MD

Heart and Vascular Center, MetroHealth,

Cleveland; Associate Professor, Case Western

Reserve University School of Medicine,

Cleveland, $\mathrm{OH}$

\title{
Procedures and devices to treat resistant hypertension in chronic kidney disease
}

\section{ABSTRACT}

Treatment of resistant hypertension is a challenge, especially in patients who have chronic kidney disease. The choice of medications may be limited in this group, making the possibility of device-based therapies attractive. We explore 4 devices and procedures available to treat this vexing issue.

\section{KEY POINTS}

Placing a shunt between the iliac artery and iliac vein (arteriovenous coupling) relieves the arterial pressure hemodyamically; this approach is experimental.

Catheter ablation of sympathetic nerve endings in the renal artery leads to less activation of the renin-angiotensin-aldosterone system and lower blood pressure; this procedure is experimental as well.

A third experimental approach to lowering blood pressure is stimulation of the carotid baroreceptors with an implanted pacemaker or stent device.

For patients with renal artery stenosis, percutaneous revascularization with stent placement can be considered; the current American College of Cardiology/American Heart Association guidelines give the procedure a class lla recommendation.

Dr. Rader has disclosed consulting for ReCor Medical.

doi:10.3949/ccjm.87a.19099
Onpharmacologic, device-based anti1 hypertensive treatments show potential, but, except for stenting of the renal arteries in patients who have renal artery stenosis, all remain experimental. Researchers have focused on patients with chronic kidney disease (CKD) and resistant hypertension, a group at high risk, in whom the benefit may justify the risk and cost of the treatment.

See related editorial, page 444

Nonpharmacologic procedure-based treatments that could in theory provide a permanent cure would be welcome in this group of patients. We discuss the role of several procedure-based treatments, ie, arteriovenous coupling, renal sympathetic denervation, baroreflex activation, and renal percutaneous revascularization in the management of resistant hypertension (Table 1 ).

\section{RESISTANT HYPERTENSION IS COMMON IN CKD}

Resistant hypertension is defined as blood pressure that remains above goal despite concurrent use of 3 antihypertensive agents of different classes ( 1 of which is a diuretic) at their maximum tolerated doses, or controlled blood pressure with the use of 4 or more agents. ${ }^{1}$

The prevalence of true resistant hypertension is difficult to ascertain, and patients suspected of having it should undergo a meticulous search for reversible causes (Table 2).

$\mathrm{CKD}$, defined by the presence of kidney damage or decreased kidney function for 3 or more months irrespective of the cause, 
TABLE 1

Advantages and limitations of antihypertensive procedures

\begin{tabular}{ll} 
Type of procedural therapy & Advantages \\
\hline Arteriovenous & Improves measures of arterial stiffness \\
coupling & Reduces overall systemic vascular \\
& resistance \\
Increases cardiac output and arterial \\
blood oxygen content
\end{tabular}

Limitations

Development of venous iliac stenosis proximal to the anastomosis

Potential risk of restenosis, and need for antithrombotic therapies

Compression stockings need to be used after device insertion

Potential for high-output cardiac failure

\begin{tabular}{lll}
\hline Renal denervation therapy & $\begin{array}{l}\text { Potential reduction of increased sympa- } \\
\text { thetic activity } \\
\text { Percutaneous ambulatory procedure }\end{array}$ & $\begin{array}{l}\text { Lacks a procedural end point } \\
\text { Variable effects on blood pressure due to } \\
\text { variability in degree of denervation achieved }\end{array}$ \\
\hline Baroreflex activation therapy & $\begin{array}{l}\text { Attenuates overall sympathetic } \\
\text { activation } \\
\text { Potential for neurohormonal modulation }\end{array}$ & $\begin{array}{l}\text { Need for subcutaneous internal pulse } \\
\text { generator with some systems }\end{array}$ \\
$\begin{array}{ll}\text { Heterogeneity in the response to carotid sinus } \\
\text { stimulation }\end{array}$ \\
\hline Renal artery stenting & $\begin{array}{l}\text { Requirement of surgical neck dissection } \\
\text { Potential to avoid surgery to treat } \\
\text { stenosis } \\
\text { Rapid improvement of global renal } \\
\text { ischemia with bilateral lesions } \\
\text { Potential to lessen sudden cardiac } \\
\text { disturbance syndromes }\end{array}$ & $\begin{array}{l}\text { Discordance between procedural success and } \\
\text { clinical improvement }\end{array}$ \\
\hline $\begin{array}{l}\text { Risk of contrast-induced nephropathy } \\
\text { Need for surveillance for stent restenosis }\end{array}$ & \begin{tabular}{l} 
Complications related to femoral access \\
\hline
\end{tabular}
\end{tabular}

presents a unique challenge in patients with resistant hypertension. ${ }^{2-4}$ The prevalence of apparent treatment-resistant hypertension in this group is estimated to range from $23 \%$ to $42 \%$, and it is associated with worse prognosis. ${ }^{5-7}$ Maintaining normal blood pressure can be difficult, given features that are common in CKD such as accelerated atherosclerosis, fluctuating volume status, inability to use the full spectrum of antihypertensive medications due to increased adverse effects, and related nonadherence issues. ${ }^{8}$ The task is made more challenging by the revised hypertension guidelines, ${ }^{2}$ which encourage clinicians to target blood pressure below 130/80 mm Hg in patients with CKD.

\section{ARTERIOVENOUS COUPLING}

Peripheral arteriovenous fistulae created for hemodialysis access are known to reduce vascular resistance. Based on this principle, there have been efforts to add a low-resistance, high-compliance venous tract parallel to the high-pressure systemic arterial circulation to reduce arterial resistance and pressure. ${ }^{9}$

The ROX coupler (ROX Medical, San Clemente, CA) is a device placed between the distal iliac vein and artery to create a central arteriovenous anastomosis (Figure 1).

\section{Trial of arteriovenous coupling}

In an initial trial, ${ }^{10} 44$ patients were randomly assigned to receive the device and 39 were assigned to receive normal care. Six months lat- 


\section{TABLE 2}

\section{Possible causes of difficult-to-treat hypertension}

Suboptimal antihypertensive therapy

Nonadherence

Lifestyle choices (eg, high-sodium diet, smoking)

Dietary indiscretion

Over-the-counter medications and supplements

Older age

Intravascular and extracellular volume expansion

Primary hyperaldosteronism

Renal artery stenosis

Renal parenchymal disease

Obstructive sleep apnea

Coarctation of the aorta

Cushing disease

Hyperparathyroidism

Pheochromocytoma

er, office systolic blood pressure had dropped by a mean of 26.9 (standard deviation 23.9) $\mathrm{mm} \mathrm{Hg}$ in the device group $(P<.0001)$ and by $3.7(21.2) \mathrm{mm} \mathrm{Hg}$ in the control group ( $P$ $=.31$ ).

There was no deterioration in renal function at 6 months, though patients with advanced CKD (estimated glomerular filtration rate $[\mathrm{eGFR}]<30 \mathrm{~mL} / \mathrm{min} / 1.73 \mathrm{~m}^{2}$ ) were excluded from the study. ${ }^{10}$ However, the trial lacked a sham treatment control group, treatment adherence was not verified, and proximal venous stenosis developed in nearly $29 \%$ of the intervention group, tempering the positive results. ${ }^{11}$

A subsequent trial was planned that would have included a control group undergoing a sham procedure, but it seems to have been terminated by the sponsor. ${ }^{12}$

\section{Prospects for arteriovenous coupling}

It remains unclear at this stage if arteriovenous coupling has the potential to become a mainstream procedure.

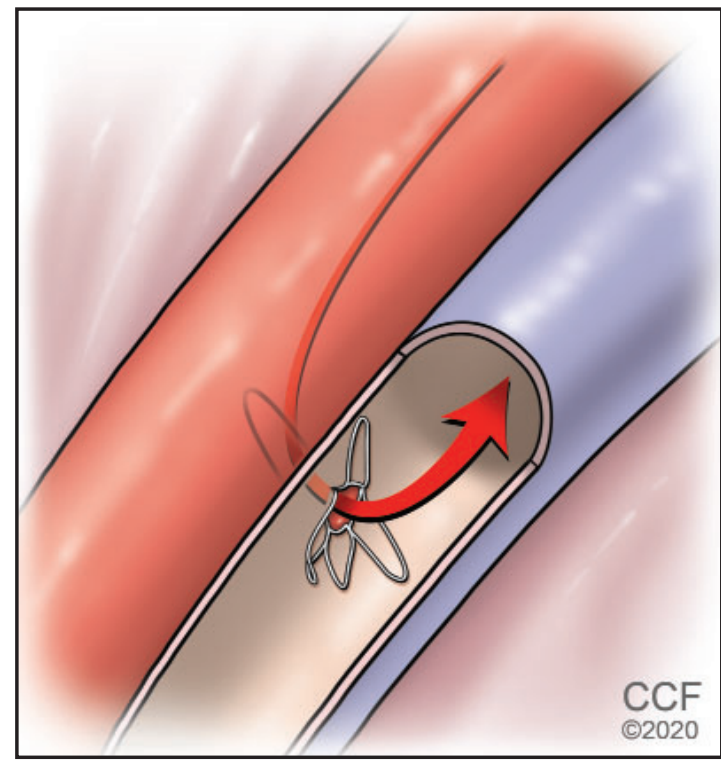

Figure 1. A percutaneously placed device creates an arteriovenous anastomosis.

\section{RENAL SYMPATHETIC DENERVATION}

Hyperactivity of the sympathetic nervous system is known to be a major factor in sustaining resistant hypertension. Curtailing this hyperactivity to better control blood pressure is a potential treatment for resistant hypertension. ${ }^{13,14}$ With this view, catheter-based devices have been developed to ablate the sympathetic afferent and efferent nerves of the renal artery by radiofrequency or ultrasound energy (Figure 2) or by transarterial injection of caustic substances. ${ }^{15}$

\section{Trials of renal sympathetic denervation}

Despite success in early studies, subsequent trials have had discouraging results. ${ }^{16}$ Pooled data from 3 sham-procedure-controlled trials of first-generation devices showed no significant reduction in blood pressure on summary treatment estimates (weighted mean difference $2.23 \mathrm{~mm} \mathrm{Hg}, 95 \%$ confidence interval [CI] -4.70 to $0.25 \mathrm{~mm} \mathrm{Hg} ; P=.08) .{ }^{17}$

Most of these trials excluded patients with eGFRs lower than $45 \mathrm{~mL} / \mathrm{min} / 1.73 \mathrm{~m}^{2}$, but even so, renal denervation did not seem to have a major deleterious effect on renal function. In the non-sham-controlled SYMPATHY trial $(\mathrm{N}=139)$, the average eGFR was $77 \pm 19 \mathrm{~mL} / \mathrm{min} / 1.73 \mathrm{~m}^{2}$ at baseline and declined by $1.5(-3.1$ to 0.1$) \mathrm{mL} / \mathrm{min} / 1.73 \mathrm{~m}^{2}$ at 6 months, with no difference between the

\section{Guidelines} encourage clinicians to target blood

pressure $<130 / 80 \mathrm{~mm} \mathrm{Hg}$ in patients with CKD 


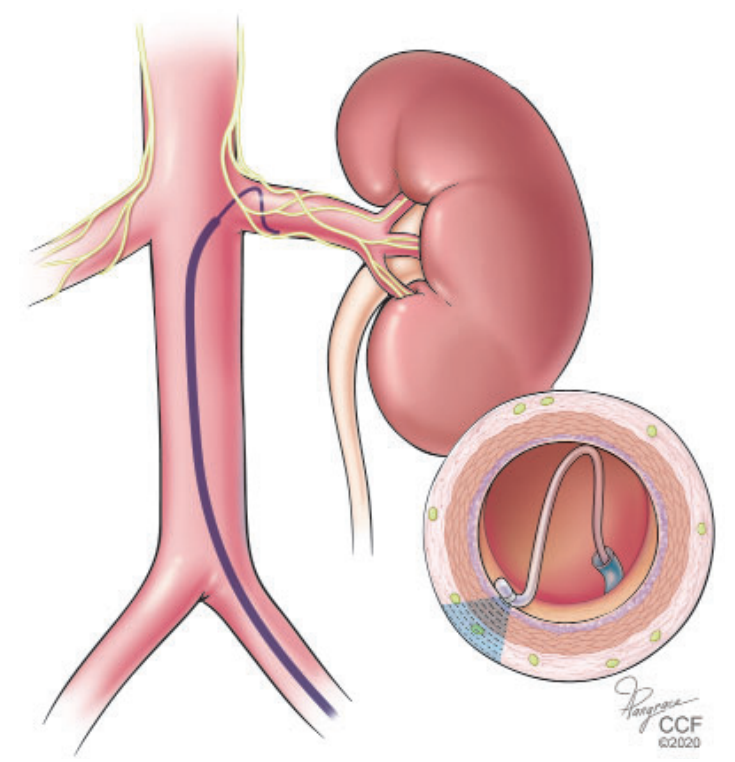

Figure 2. Renal artery denervation is performed using an intra-arterial catheter.

groups receiving renal denervation and usual medical care. ${ }^{18,19}$

A subsequent sham-controlled trial set out to include participants with low eGFR, but only $3 \%$ of the denervation treatment group had eGFRs between 30 and $45 \mathrm{~mL} / \mathrm{min} / 1.73$

It is unclear at this stage if arteriovenous coupling has the potential to become a mainstream procedure $\mathrm{m}^{2}$; most (92\%) had eGFRs higher than 60. There was no detectable change in renal function after the procedure. ${ }^{20}$

In recent sham-controlled trials, novel second-generation devices seemed to hold promise. In the SPYRAL HTN-ON MED and OFF-MED trials, ${ }^{21,22}$ renal denervation using the Symplicity Spyral device (Medtronic, Dublin, Ireland) led to statistically significant and clinically meaningful blood pressure reduction at 6 months; the mean 24-hour systolic blood pressure had dropped by $7.0 \mathrm{~mm} \mathrm{Hg}$ (95\% CI -12.0 to $-2.1 ; P=.0059)$. Patients with eGFR less than $45 \mathrm{~mL} / \mathrm{min} / 1.73 \mathrm{~m}^{2}$ were excluded, but no patient in the entire cohort had a serum creatinine elevation greater than $50 \%$, and no new or worsening renal failure was reported.

The RADIANCE-HTN SOLO trial $^{23}$ showed that renal denervation with the Paradise system (ReCor Medical, Palo Alto, CA) reduced daytime ambulatory systolic blood pressure in 74 patients ( 8.5 vs $2.2 \mathrm{~mm} \mathrm{Hg}$; $<.0001)$. While patients with eGFR less than 40 were not recruited, there were no signifi- cant changes in eGFR between the treatment groups (adjusted mean difference -0.6, 95\% CI -4.4 to $3.2, P=.75)$.

\section{Cost-effectiveness of renal denervation}

Geisler et $\mathrm{al}^{24}$ calculate that the discounted lifetime incremental cost-effectiveness ratio for renal denervation therapy is $\$ 3,071$ per quality-adjusted life-year, and the $95 \%$ credible interval for incremental cost-effectiveness ratio is $\$ 31,460$ per quality-adjusted life-year.

Chowdhury et $\mathrm{a}^{25}$ report that over a lifetime at the current estimated costs, renal denervation it would be cost-effective only if it were targeted to patients whose 10 -year predicted cardiovascular risk was at least $13.2 \%$ initially.

\section{Prospects for renal denervation}

Improvement in the design of renal denervation delivery could overcome some of the procedural setbacks of earlier trials. This, and better selection of patients, may lead to acceptable results of renal denervation in the near future. Experience suggests that patients who have mild CKD may tolerate this treatment well. However, well-designed, adequately powered trials to evaluate the long-term efficacy and safety of second-generation renal denervation technology in patients with resistant hypertension with all stages of CKD are needed to validate the safety of this treatment in CKD.

\section{BAROREFLEX ACTIVATION THERAPY}

Another approach to reducing sympathetic tone to help control blood pressure is electric stimulation of the carotid sinus baroreceptors. ${ }^{26}$ The first-generation Rheos system (CVRx, Minneapolis, MN) consisted of a pacemaker unit implanted subcutaneously in the infraclavicular position along with electrodes leading to both carotids. ${ }^{27}$

\section{Studies of baroreflex activation therapy}

Early studies using the Rheos system in 383 patients showed that substantial blood pressure reduction was maintained over a followup of 6 years. ${ }^{28}$ Patients on dialysis were generally excluded from these trials, and those with CKD made up only a small portion of the cohort $(<15 \%)$.

In a follow-up study of 236 patients from 
the Rheos Pivotal trial, the mean eGFR decreased from $92 \pm 20 \mathrm{~mL} / \mathrm{min}$ at baseline to 87 $\pm 22 \mathrm{~mL} / \mathrm{min}$ at 6 months in the active therapy group and to $85 \pm 23 \mathrm{~mL} / \mathrm{min}$ in the control group $(P=.589)$. Given the drop in eGFR in both groups, this decrease could merely represent the normal decline of renal function over time. In the relatively small subgroup of patients with an eGFR less than $60 \mathrm{~mL} / \mathrm{min}$ $(\mathrm{n}=18$, mean eGFR $49 \pm 8 \mathrm{~mL} / \mathrm{min})$, renal function remained stable over a 12-month observation period. ${ }^{29}$

The second-generation Neo system (also from CVRx), which uses a smaller electrode, was developed to mitigate some of the procedure-related complications such as cranial nerve injuries associated with the use of firstgeneration Rheos.

In a pilot study in 23 patients with CKD and resistant hypertension who were treated with the second-generation Neo system, there was a significant decrease in the mean arterial blood pressure $(116.9 \pm 20.9 \mathrm{~mm} \mathrm{Hg}$ before vs $104.2 \pm 22.2 \mathrm{~mm} \mathrm{Hg}$ after the procedure). Patients who had stage 3 or 4 CKD experienced a greater reduction in proteinuria, and the eGFR remained stable in the treated patients despite the reduction of systemic blood pressure. $^{30}$

The MobiusHD device (Vascular Dynamics, Mountain View, CA), another secondgeneration device, is a catheter-delivered self-expanding intracarotid implant designed to activate the baroreflex (Figure 3). ${ }^{31}$ In its first study in humans, it seemed successful in reducing blood pressure, and a larger trial designed to evaluate the safety and effectiveness of the MobiusHD device is actively enrolling patients. ${ }^{31,32}$ Again the long-term efficacy and safety of second-generation baroreflex activation devices in patients with resistant hypertension and CKD of all stages is yet to be verified in large randomized controlled trials.

\section{Cost-effectiveness}

\section{of baroreceptor stimulation}

Borisenko et $\mathrm{al}^{33}$ calculate that baroreceptor stimulation therapy generates 1.66 additional life-years and 2.17 additional quality-adjusted life years at an incremental cost of $€ 16,891$ compared with continued medical management in a simulated cohort of 50-year-old pa-

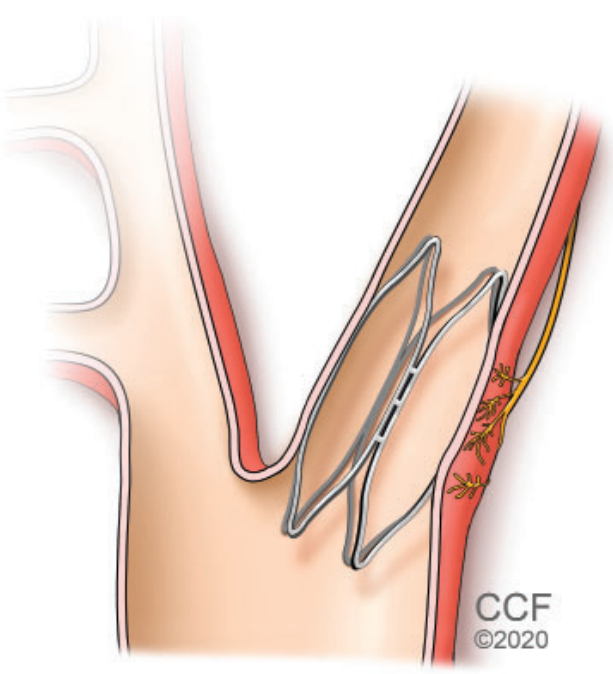

Figure 3. A percutaneously placed implant is designed to stimulate the carotid baroreceptors and thus lower blood pressure.

tients at high risk of end-organ damage. Baroreceptor stimulation was estimated to be cost-effective compared with optimal medical treatment with an incremental cost-effectiveness ratio of $€ 7,797$ per quality-adjusted life year.

However, an independent assessment by the Norwegian Institute of Public Health noted that based on incremental cost-effectiveness ratio levels and after adjusting the model to account for important shortcomings in the submitted analysis related to clinical effect and health-related quality of life, the incremental cost-effectiveness ratio rises well above the level that has been considered costeffective in Norway. ${ }^{34}$

\section{RENAL ARTERY STENTING}

Renal artery stenosis compromises blood flow to the kidneys, activating the renin-angiotensin-aldosterone axis and causing hypertension. In more than $90 \%$ of cases, renal artery stenosis is due to atherosclerosis, usually affecting the ostial part of the renal artery. ${ }^{35}$

Clinicians are encouraged to suspect renal artery stenosis and to look for it in patients with resistant hypertension, as it has been noted to be present in up to $24 \%$ of these patients. ${ }^{36}$ Risk factors and specific clinical presentations that raise suspicion for renal artery stenosis are presented in Table 3 and Table 4.
Trials are needed to validate the safety of renal denervation therapy in CKD 


\section{TABLE 3}

\section{Causes of renal artery stenosis}

Atherosclerosis

Fibromuscular dysplasia

Nephroangiosclerosis (hypertensive injury)

Diabetic nephropathy (small-vessel)

Renal thromboembolic disease

Atheroembolic renal disease

Aortorenal dissection

Renal artery vasculitis

Trauma

Neurofibromatosis

Thromboangiitis obliterans

Scleroderma

Extrinsic compression

\section{TABLE 4}

\section{Clues to the presence of renal artery stenosis}

\section{Clinicians are encouraged to suspect renal artery stenosis in patients with resistant hypertension}

Onset of hypertension before age 30

Onset of severe hypertension after age 55

Resistant hypertension

Hypertensive urgencies

New renal impairment after starting angiotensinconverting enzyme inhibitor therapy

Optimal medical therapy remains the preferred treatment of atherosclerotic renal artery stenosis. Major society guidelines emphasize optimal medical therapy with blockade of the renin-angiotensin-aldosterone axis to confer survival benefit in these patients. ${ }^{37}$

However, clinicians and researchers have long hoped that procedural intervention could relieve renal artery stenosis, cure the hypertension, and eliminate the burden of lifelong medical therapy. Pioneering work by Grüntzig et $\mathrm{al}^{38}$ with balloon angioplasty of renal artery stenosis showed significant relief of hypertension. The subsequent development of vascular

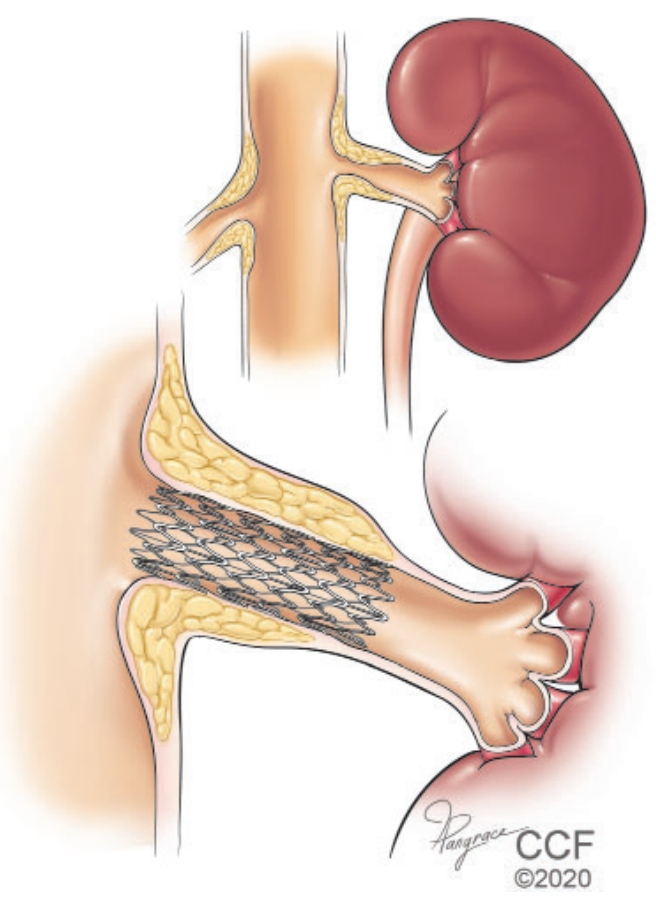

Figure 4. Stenting is reasonable for treating resistant hypertension in patients with significant renal artery stenosis.

stents led to percutaneous revascularization by stenting as the preferred technique to resolve renal artery stenosis (Figure 4). ${ }^{39}$

Early case series and registries seemed to validate the utility of percutaneous resvascularization as a treatment for renal artery stenosis. In a nonrandomized single-arm study of 202 patients (with 241 total lesions), percutaneous resvascularization lowered the mean systolic blood pressure from $162 \mathrm{~mm} \mathrm{Hg}$ at baseline to $145 \mathrm{~mm} \mathrm{Hg}$ at 9 months $(P<$ $.0001)$, while the eGFR remained nearly the same at 58 vs $57 \mathrm{~mL} / \mathrm{min} / 1.73 \mathrm{~m}^{2}(P=.38){ }^{40}$

However, these results could not be replicated in various subsequent randomized controlled trials. ${ }^{41}$ Analysis of 8 trials, which included 2,223 patients, showed that renal artery revascularization was not associated with a change in systolic blood pressure from baseline when compared with medical therapy (weighted mean difference $0.12,95 \% \mathrm{CI}$ -0.97 to $1.21, P=.83$ ). Moreover, revascularization was not associated with a reduced incidence of adverse cardiovascular or renal outcomes, and the results seemed similar when restricted to 5 stent-only trials. ${ }^{41}$ 


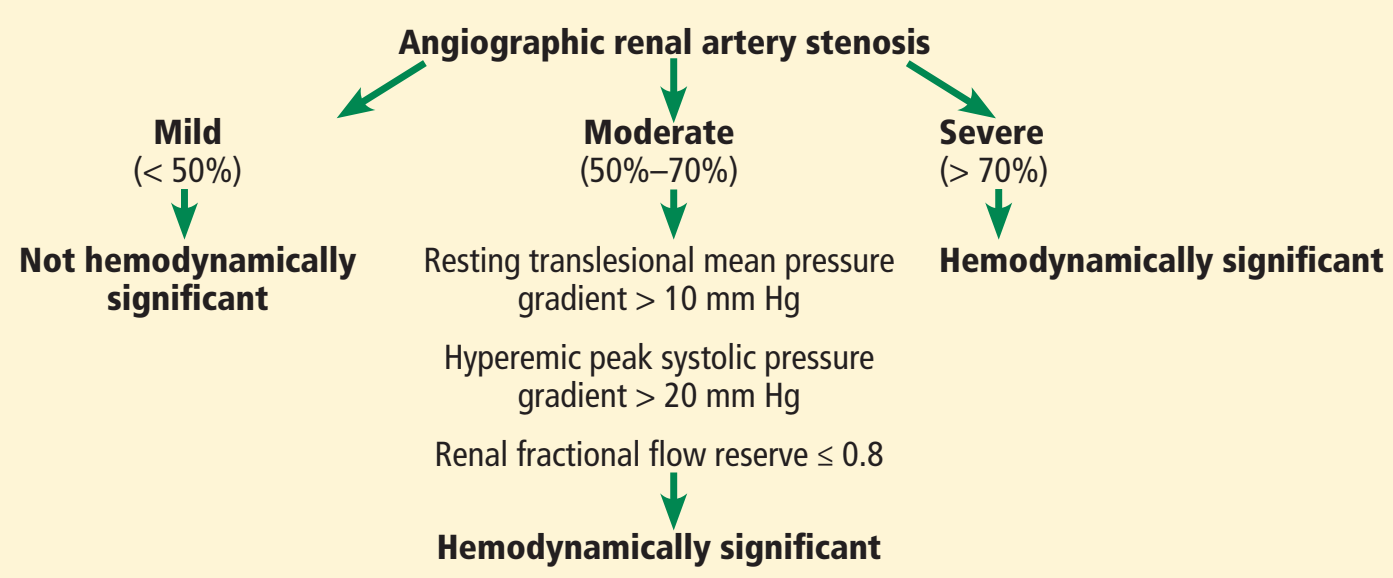

Figure 5. Hemodynamic significance of angiographic renal artery stenosis.

However, the randomized controlled trials may not tell the whole story. Design flaws, patient selection, and enrollment bias in various published trials may limit their clinical applicability, especially in patients who might benefit the most. ${ }^{42}$

There hence seems to be a broad expert consensus that certain groups of patients with severe renal artery stenosis should be treated with revascularization. The current American College of Cardiology/American Heart Association guidelines on the management of peripheral arterial disease give the procedure a class IIa recommendation (level of evidence B), stating that percutaneous revascularization "is reasonable" for patients with hemodynamically significant renal artery stenosis and resistant hypertension..$^{37,43}$ Similarly, a Society for Cardiovascular Angiography and Interventions statement also suggests percutaneous revascularization may be considered as appropriate care in patients with significant renal artery stenosis and resistant hypertension. ${ }^{44}$

Figure 5 presents diagnostic criteria for significant renal artery stenosis and outlines when percutaneous revascularization can be considered.

Renal outcomes after percutaneous revascularization have varied. In one of the largest randomized controlled trials to date, the Cardiovascular Outcomes in Renal Atherosclerotic Lesions (CORAL study), with 947 patients in total, the rates of end points were similar between the percutaneous revascularization group and the medical therapy-only group at 43 months of follow-up, including death from renal causes ( 2 cases vs $1, P=.6$ ), progressive renal failure ( 77 vs $89, P=.34$ ), and need for permanent renal replacement therapy (16 vs $8, P=.11){ }^{45}$

In the Angioplasty and Stenting for Renal Artery Lesions (ASTRAL) trial, ${ }^{46}$ with 806 randomized patients, the rate of progression of renal impairment was slightly slower in the revascularization group than in the medical group $\left(-0.07 \times 10^{-3} \mathrm{~L} / \mu \mathrm{mol} /\right.$ year vs $-0.13 \times$ $10^{-3} \mathrm{~L} / \mu \mathrm{mol} /$ year; $P=.06$ ) over 5 years of follow-up. Over the same time, the mean serum creatinine level was $1.6 \mu \mathrm{mol} / \mathrm{L}$ lower in the revascularization group than in the medical therapy group.

Thus, percutaneous revascularization for renal artery stenosis seems to have a reasonable renal safety profile even in patients with CKD.

\section{Cost-effectiveness of percutaneous revascularization}

In a German study ${ }^{47}$ analyzing the cost-effectiveness of medical therapy, percutaneous transluminal angioplasty with and without a stent, and surgery for the therapy of renalartery stenoses in hypertensive patients, the average reimbursed treatment cost per patient after 3 years was as follows:

- $€ 9,121$ for medication

- $€ 17,164$ for surgery

- $€ 14,670$ for percutaneous angioplasty

- $€ 8,437$ for stenting.

This resulted in cost-effectiveness ratios
Percutaneous revascularization for renal artery stenosis seems to have a reasonable renal safety profile even in patients with CKD 
per event-free patient at 3 years as follows:

- $€ 51,752$ for medical treatment

- $€ 36,454$ for surgery

- $€ 78,766$ for percutaneous angioplasty

- $€ 11,663$ for stenting.

The researchers concluded that a strategy

of primary stent implantation is more cost-effective than stand-alone balloon dilatation. ${ }^{47}$

\section{THESE TREATMENTS MAY PROVE USEFUL}

Nonpharmacologic treatments for resistant and difficult-to-treat hypertension in patients with CKD may prove to be useful. Percutaneous revascularization may be considered in patients with resistant hypertension and underlying renal artery stenosis.

\section{REFERENCES}

1. Calhoun DA, Jones D, Textor S, et al; American Heart Association Professional Education Committee. Resistant hypertension: diagnosis, evaluation, and treatment: a scientific statement from the American Heart Association Professional Education Committee of the Council for High Blood Pressure Research. Circulation 2008; 117(25):e510e526. doi:10.1161/CIRCULATIONAHA.108.189141

2. Whelton PK, Carey RM, Aronow WS, et al. 2017 ACC/AHA/AAPA/ABC/ ACPM/AGS/APhA/ASH/ASPC/NMA/PCNA guideline for the prevention, detection, evaluation, and management of high blood pressure in adults: a report of the American College of Cardiology/American Heart Association Task Force on Clinical Practice Guidelines. J Am Coll Cardiol 2018; 71(19):e127-e248. doi:10.1016/j.jacc.2017.11.006

3. Inker LA, Astor BC, Fox CH, et al. KDOQI US commentary on the 2012 KDIGO clinical practice guideline for the evaluation and management of CKD. Am J Kidney Dis 2014; 63(5):713-735. doi:10.1053/j.ajkd.2014.01.416

4. Chapter 1: Definition and classification of CKD. Kidney Int Suppl (2011) 2013; 3(1):19-62. doi:10.1038/kisup.2012.64

5. Noubiap JJ, Nansseu JR, Nyaga UF, Sime PS, Francis I, Bigna JJ. Global prevalence of resistant hypertension: a meta-analysis of data from 3.2 million patients. Heart 2019; 105(2):98-105. doi:10.1136/heartjnl-2018-313599

6. Thomas G, Xie D, Chen HY, et al. Prevalence and prognostic significance of apparent treatment resistant hypertension in chronic kidney disease: report from the Chronic Renal Insufficiency Cohort Study. Hypertension 2016; 67(2):387-396. doi:10.1161/HYPERTENSIONAHA.115.06487

7. Muntner P, Anderson A, Charleston J, et al; Chronic Renal Insufficiency Cohort (CRIC) Study Investigators. Hypertension awareness, treatment, and control in adults with CKD: results from the Chronic Renal Insufficiency Cohort (CRIC) Study. Am J Kidney Dis 2010; 55(3):441-451. doi:10.1053/j.ajkd.2009.09.014

8. Rossignol P, Massy ZA, Azizi M, et al; ERA-EDTA EURECA-m working group; Red de Investigación Renal (REDINREN) network; Cardiovascular and Renal Clinical Trialists (F-CRIN INI-CRCT) network. The double challenge of resistant hypertension and chronic kidney disease. Lancet 2015; 386(10003):1588-1598. doi:10.1016/S0140-6736(15)00418-3

9. Kapil V, Sobotka PA, Saxena M, et al. Central iliac arteriovenous anastomosis for hypertension: targeting mechanical aspects of the circulation. Curr Hypertens Rep 2015; 17(9):585. doi:10.1007/s11906-015-0585-6

10. Lobo MD, Sobotka PA, Stanton A, et al; ROX CONTROL HTN Investigators. Central arteriovenous anastomosis for the treatment of
Ongoing trials have demonstrated the efficacy and safety of newer renal denervation and baroreflex activation devices, but more data are needed regarding treating the difficult subgroup of hypertensive patients who have CKD of all stages. The concept of reducing pill burden and increasing medication adherence remains attractive and has a large potential for improving outcomes in this high-risk group.

We would like to emphasize that except for renal artery stenting, the therapies discussed here remain experimental and are not approved by the US Food and Drug Administration for routine clinical use except as part of clinical trials.

patients with uncontrolled hypertension (the ROX CONTROL HTN study): a randomised controlled trial. Lancet 2015; 385(9978):16341641. doi:10.1016/S0140-6736(14)62053-5

11. Schlaich $\mathbf{M}$, Hering D. Central arteriovenous anastomosis in resistant hypertension? Lancet 2015; 385(9978):1596-1597. doi:10.1016/S0140-6736(14)62290-X

12. National Library of Medicine. A multicenter study to evaluate the ROX coupler in subjects with hypertension (CONTROL HTN-2). ClinicalTrials.gov Identifier: NCT02895386. https://clinicaltrials.gov/ct2/ show/NCT02895386. Accessed June 10, 2020.

13. Huan Y, Cohen DL. Renal denervation: a potential new treatment for severe hypertension. Clin Cardiol 2013; 36(1):10-14. doi:10.1002/clc.22071

14. Schlaich MP. Renal sympathetic denervation: a viable option for treating resistant hypertension. Am J Hypertens 2017; 30(9):847-856. doi:10.1093/ajh/hpx033

15. Krum H, Schlaich M, Whitbourn R, et al. Catheter-based renal sympathetic denervation for resistant hypertension: a multicentre safety and proof-of-principle cohort study. Lancet 2009; 373(9671):12751281. doi:10.1016/S0140-6736(09)60566-3

16. Coppolino G, Pisano A, Rivoli L, Bolignano D. Renal denervation for resistant hypertension. Cochrane Database Syst Rev 2017; 2:CD011499. doi:10.1002/14651858.CD011499.pub2

17. Sardar P, Bhatt DL, Kirtane AJ, et al. Sham-controlled randomized trials of catheter-based renal denervation in patients with hypertension. J Am Coll Cardiol 2019; 73(13):1633-1642. doi:10.1016/j.jacc.2018.12.082

18. Vink EE, de Beus $E$, de Jager RL, et al. The effect of renal denervation added to standard pharmacologic treatment versus standard pharmacologic treatment alone in patients with resistant hypertension: rationale and design of the SYMPATHY trial. Am Heart J 2014; 167(3):308-314.e3. doi:10.1016/j.ahj.2013.11.010

19. de Jager RL, de Beus E, Beeftink MM, et al; SYMPATHY Investigators Impact of medication adherence on the effect of renal denervation: the SYMPATHY Trial. Hypertension 2017; 69(4):678-684. doi:10.1161/HYPERTENSIONAHA.116.08818

20. Mathiassen ON, Vase $H$, Bech JN, et al. Renal denervation in treatment-resistant essential hypertension. A randomized, SHAM-controlled, double-blinded 24-h blood pressure-based trial. J Hypertens 2016; 34(8):1639-1647. doi:10.1097/HJH.0000000000000977

21. Townsend RR, Mahfoud F, Kandzari DE, et al; SPYRAL HTN-OFF MED trial investigators. Catheter-based renal denervation in patients with uncontrolled hypertension in the absence of antihypertensive medications (SPYRAL HTN-OFF MED): a randomised, sham-controlled, proof-of-concept trial. Lancet 2017; 390(10108):2160-2170. doi:10.1016/S0140-6736(17)32281-X 
22. Kandzari DE, Böhm M, Mahfoud F, et al; SPYRAL HTN-ON MED Trial Investigators. Effect of renal denervation on blood pressure in the presence of antihypertensive drugs: 6-month efficacy and safety results from the SPYRAL HTN-ON MED proof-of-concept randomised trial. Lancet 2018; 391(10137):2346-2355. doi:10.1016/S0140-6736(18)30951-6

23. Azizi M, Schmieder RE, Mahfoud F, et al; RADIANCE-HTN Investigators. Endovascular ultrasound renal denervation to treat hypertension (RADIANCE-HTN SOLO): a multicentre, international, single-blind, randomised, sham-controlled trial. Lancet 2018; 391(10137):2335-2345. doi:10.1016/50140-6736(18)31082-1.

24. Geisler BP, Egan BM, Cohen JT, et al. Cost-effectiveness and clinical effectiveness of catheter-based renal denervation for resistant hypertension. J Am Coll Cardiol 2012; 60(14):1271-1277. doi:10.1016/j.jacc.2012.07.029

25. Chowdhury EK, Reid CM, Zomer E, Kelly DJ, Liew D. Cost-effectiveness of renal denervation therapy for treatment-resistant hypertension: a best case scenario. Am J Hypertens 2018; 31(10):1156-1163. doi:10.1093/ajh/hpy108

26. Heusser K, Tank J, Engeli S, et al. Carotid baroreceptor stimulation, sympathetic activity, baroreflex function, and blood pressure in hypertensive patients. Hypertension 2010; 55(3):619-626. doi:10.1161/HYPERTENSIONAHA.109.140665

27. Bisognano JD, Bakris G, Nadim MK, et al. Baroreflex activation therapy lowers blood pressure in patients with resistant hypertension: results from the double-blind, randomized, placebo-controlled Rheos Pivotal Trial. J Am Coll Cardiol 2011; 58(7):765-773. doi:10.1016/j.jacc.2011.06.008

28. de Leeuw PW, Bisognano JD, Bakris GL, Nadim MK, Haller H, Kroon AA; DEBuT-HT and Rheos Trial Investigators. Sustained reduction of blood pressure with baroreceptor activation therapy: results of the 6-year open follow-up. Hypertension 2017; 69(5):836-843. doi:10.1161/HYPERTENSIONAHA.117.09086

29. Wallbach M, Koziolek MJ. Baroreceptors in the carotid and hypertension-systematic review and meta-analysis of the effects of baroreflex activation therapy on blood pressure. Nephrol Dial Transplant 2018; 33(9):1485-1493. doi:10.1093/ndt/gfx279

30. Wallbach M, Böhning E, Lehnig LY, et al. Safety profile of baroreflex activation therapy (NEO) in patients with resistant hypertension. J Hypertens 2018; 36(8):1762-1769. doi:10.1097/HJH.0000000000001753

31. Spiering W, Williams B, Van der Heyden J, et al; CALM-FIM_EUR investigators. Endovascular baroreflex amplification for resistant hypertension: a safety and proof-of-principle clinical study. Lancet 2017; 390(10113):2655-2661. doi:10.1016/S0140-6736(17)32337-1

32. Williams B, Stone G. Introduction of the CALM II study: a multi-center, blinded, sham-controlled pivotal trial of an endovascular carotid barostimulation implant for the treatment of resistant hypertension. J Am Coll Cardiol 2017; 69(11 suppl):1726. doi:10.1016/S0735-1097(17)35115-X

33. Borisenko O, Beige J, Lovett EG, Hoppe UC, Bjessmo S. Cost-effectiveness of barostim therapy for the treatment of resistant hypertension in European settings. J Hypertens 2014; 32(3):681-692. doi:10.1097/HJH.0000000000000071

34. Pike E, Fagerlund BC, Giske L, Desser A, Harboe I. Baroreflex activation therapy for drug-resistant hypertension: a single technology assessment. Report from the Norwegian Institute of Public Health No. 2017-17. https://www.ncbi.nlm.nih.gov/books/NBK482090/. Accessed June 10, 2020.
35. Chrysochou C, Kalra PA. Epidemiology and natural history of atherosclerotic renovascular disease. Prog Cardiovasc Dis 2009; 52(3):184195. doi:10.1016/j.pcad.2009.09.001

36. Benjamin MM, Fazel P, Filardo G, Choi JW, Stoler RC. Prevalence of and risk factors of renal artery stenosis in patients with resistant hypertension. Am J Cardiol 2014; 113(4):687-690. doi:10.1016/j.amjcard.2013.10.046

37. Rooke TW, Hirsch AT, Misra S, et al; American College of Cardiology Foundation Task Force; American Heart Association Task Force. Management of patients with peripheral artery disease (compilation of 2005 and 2011 ACCF/AHA Guideline Recommendations): a report of the American College of Cardiology Foundation/American Heart Association Task Force on Practice Guidelines. J Am Coll Cardiol 2013; 61(14):1555-1570. doi:10.1016/j.jacc.2013.01.004

38. Grüntzig A, Kuhlmann U, Vetter W, Lütolf U, Meier B, Siegenthaler W. Treatment of renovascular hypertension with percutaneous transluminal dilatation of a renal-artery stenosis. Lancet 1978; 1(8068):801-802. doi:10.1016/50140-6736(78)93000-3

39. Dorros G, Jaff M, Mathiak L, He T; Multicenter Registry Participants. Multicenter Palmaz stent renal artery stenosis revascularization registry report: four-year follow-up of 1,058 successful patients. Catheter Cardiovasc Interv 2002; 55(2):182-188. doi:10.1002/ccd.3050

40. Jaff MR, Bates M, Sullivan T, et al; HERCULES Investigators. Significant reduction in systolic blood pressure following renal artery stenting in patients with uncontrolled hypertension: results from the HERCULES trial. Catheter Cardiovasc Interv 2012; 80(3):343-350. doi:10.1002/ccd.24449

41. Bavry AA, Kapadia SR, Bhatt DL, Kumbhani DJ. Renal artery revascularization: updated meta-analysis with the CORAL trial. JAMA Intern Med 2014; 174(11):1849-1851. doi:10.1001/jamainternmed.2014.4332

42. Patel SM, Li J, Parikh SA. Renal artery stenosis: optimal therapy and indications for revascularization. Curr Cardiol Rep 2015; 17(9):623. doi:10.1007/s11886-015-0623-7

43. Bailey SR, Beckman JA, Dao TD, et al. ACC/AHA/SCAI/SIR/SVM 2018 appropriate use criteria for peripheral artery intervention: a report of the American College of Cardiology Appropriate Use Criteria Task Force, American Heart Association, Society for Cardiovascular Angiography and Interventions, Society of Interventional Radiology, and Society for Vascular Medicine. J Am Coll Cardiol 2019; 73(2):214-237. doi:10.1016/j.jacc.2018.10.002

44. Parikh SA, Shishehbor MH, Gray BH, White CJ, Jaff MR. SCAl expert consensus statement for renal artery stenting appropriate use. Catheter Cardiovasc Interv 2014; 84(7):1163-1171. doi:10.1002/ccd.25559

45. Cooper CJ, Murphy TP, Cutlip DE, et al; CORAL Investigators. Stenting and medical therapy for atherosclerotic renal-artery stenosis. N Engl J Med 2014; 370(1):13-22. doi:10.1056/NEJMoa1310753

46. ASTRAL Investigators; Wheatley K, Ives N, Gray R, et al. Revascularization versus medical therapy for renal-artery stenosis. N Engl J Med 2009; 361(20):1953-1962. doi:10.1056/NEJMoa0905368

47. Duda SH, Banz S, Brehme U, et al. Cost-effectiveness analysis of treatment of renal-artery stenoses by medication, angioplasty, stenting and surgery. Minim Invasive Ther Allied Technol 2001; 10(1):55-65. doi:10.1080/13645700152598932

Address: Rama Dilip Gajulapalli, MD, Department of Hospital Medicine, M2 Annex, Cleveland Clinic, 9500 Euclid Avenue, Cleveland, OH 44195; GAJULAR@ccf.org 